\title{
Structural Reliability Analysis of Ship Hulls Accounting for Collision or Grounding Damage
}

\author{
Branka Bužančić Primorac ${ }^{1}$ • Joško Parunov ${ }^{2} \cdot$ C. Guedes Soares ${ }^{3}$
}

Received: 18 March 2020 / Accepted: 25 September 2020 / Published online: 20 November 2020

(C) The Author(s) 2020

\begin{abstract}
Classical structural reliability analysis of intact ship hulls is extended to the case of ships with collision or grounding damages. Still water load distribution and residual bending moment capacity are included as random variables in the limit state equation. The probability density functions of these random variables are defined based on random damage parameters given by the Marine Environment Protection Committee of the International Maritime Organization, while the proposed reliability formulation is consistent with international recommendations and thus may be valuable in the development of rules for accidental limit states. The methodology is applied on an example of an Aframax oil tanker. The proposed approach captures in a rational way complex interaction of different pertinent variables influencing safety of damaged ship structure.
\end{abstract}

Keywords Ship structures $\cdot$ Hull girder $\cdot$ Collision and grounding $\cdot$ Damaged oil tanker $\cdot$ Residual strength $\cdot$ Uncertainty modelling $\cdot$ Structural reliability

\section{Introduction}

Risk-based design is becoming an accepted design process for most ship types, providing a rational basis for making decisions on their design, operation and regulations. Risk in general can be defined as the potential of losses as a result of a system failure and depends on the probability of failure and the outcomes or consequences associated with the structural failure. Therefore, calculation of failure probabilities is a vital

\section{Article Highlights}

- Intact ship structural reliability method is extended to damaged ships

- IMO probabilistic models for collision and grounding damage parameters are employed

- The study resulted in recommendation to the classification societies that the accidental limit state check for residual bending moment capacity should be reconsidered.

Joško Parunov

jparunov@fsb.hr

$1 \quad$ Faculty of Electrical Engineering, Mechanical Engineering and Naval Architecture, University of Split, Split, Croatia

2 Faculty of Mechanical Engineering and Naval Architecture, University of Zagreb, Zagreb, Croatia

3 Centre of Marine Technology and Ocean Engineering (CENTEC) Instituto Superior Técnico, Universidade de Lisboa, Lisbon, Portugal part of risk assessment process and this is achieved by structural reliability approaches that have evolved much since the early formulations of the second moment approach applied to first yield bending moment (Mansour and Faulkner 1973) to be based on the ultimate strength of the hull girder (Guedes Soares et al. 1996), which was adopted 10 years later in the Common Structural Rules of Classification Societies (2006). Important evolutions have been the accounting for the continuous degradation and maintenance (e.g. Guedes Soares and Garbatov 1996, 1999), introducing simulation (Gaspar and Guedes Soares 2013; Gaspar et al. 2016), time-dependent (Guedes Soares and Ivanov 1989) and time-varying formulations (Zayed et al. 2013). More details on the evolution of the formulations is described in Teixeira and Guedes Soares (2009, 2010), Teixeira et al. (2011).

An important development has been the consideration of accidental damage and post-accidental hull girder behaviour of the ship structure as part of risk assessment and the design procedure. This evolution resulted from the ability to predict the residual strength of damaged structures and to assess their reliability. Statistics on marine accidents shows that collision and grounding are the two main types of ship accidents (Bužančić Primorac and Parunov 2016). Following such an accident, the ship strength is often reduced because of the damage. If the flooding of ship compartments occurs, still water loading could be considerably modified. Wave loads 
depend on the sea conditions in time of the accident and rescue duration (Hirdaris et al. 2014). A damaged ship may collapse after a collision or grounding if the hull girder loads applied exceed hull's residual strength (Gordo and Guedes Soares 1997; Guedes Soares et al. 2008; Prestileo et al. 2013). Required safety level against hull girder collapse should be maintained immediately after the accident and also during rescue operations or while ship being towed to the nearest repair yard.

Research on performance assessment of damaged structures has attracted significant interest in the last two decades, mainly focused on residual vertical bending moment capacity at the midship region. Most of these studies used assumed damage extent for evaluating the structural safety of damaged ships (Wang et al. 2002; Khan and Das 2008; Luís et al. 2009; Hussein and Guedes Soares 2009). Information from Classification Society rules (e.g. American Bureau of Shipping 1995; International Association of Classification Societies 2014) were used to deterministically define the collision or grounding damage size. Variation of such prescribed damage was also used to investigate consequences on the safety considering the residual strength. The probability of structural failure is calculated using structural reliability methods as for intact ships. Prescriptive damages are, however, a large drawback of this procedure, as they are often insufficient for innovation in structural design because they do not have clearly defined occurrence probability and may not address all possible accidental circumstances. The similar procedure, with deterministic damage description, is presented in ISSC Committee V.1 (2015a, b) for bulk carriers. However, the nature of ship collision and grounding accidents is rather uncertain, and probabilistic characterisation of damage is therefore desirable.

Structural reliability analysis (SRA) is used to develop the probability of hull girder failure for each design and each individual accident case (Luís et al. 2009; Hussein and Guedes Soares 2009; Saydam and Frangopol 2013). Such reliability calculations include appropriate definitions of uncertainties in ultimate bending moment capacity and global hull girder loadings accounting for their natural variations arising from the stochastic nature of the ocean and variability in geometric and material properties of the structure, and the inherent uncertainty with the actual engineering calculation processes themselves (Downes et al. 2007).

As each individual accident scenario can also have an individual probability of occurrence associated with it, it is necessary to combine the failure probability calculated for each individual accident case with the probability of occurrence of that scenario. The Marine Environment Protection Committee (MEPC) of the International Maritime Organization (IMO) in Resolution MEPC 110(49) Annex 16 (2003) proposed such probability distributions for cases of the collision and grounding of oil tankers, based on available tanker casualty statistics.
These probability distributions are utilised in Bayesian network models to include many possible flooding configurations due to grounding damages, different sea conditions and the effects of both on different frames along the ship (Prestileo et al. 2013). For the collision damage, scenarios are selected by using a sampling technique in which the probability density functions of the influencing parameters are characterised in a probabilistic manner, rather than using IMO probabilities (Youssef et al. 2016; Faisal et al. 2017). IMO MEPC statistical model has been updated for the collision damage case in two EU-funded projects, namely HARDER (Tagg et al. 2002) and GOALDS (Papanikolaou et al. 2011). Latter model has been used in structural reliability study of oil tanker and bulk carrier (Campanile et al. 2018a, b).

In this paper, a probabilistic framework is presented for SRA of ship hulls for random damage scenarios under collision or grounding. The procedure represents an extension of the common structural reliability methodology for intact ship, which is proposed by the Maritime Safety Committee (MSC) of IMO (MSC 81/INF.6 2006). The presented approach consists of introducing a probabilistic model for the reduction of the ultimate strength caused by the random loss of structural elements due to damage and of introducing a random modification of still water bending moment (SWBM) for the damaged ship. The bases for definition of these probabilistic models are random damage parameters defined by the MEPC of IMO Resolution MEPC 110(49) Annex 16 (2003). Therefore, the presented procedure is consistent with several different IMO recommendations providing to the procedure credibility for practical applications (MSC 81/INF.6 2006; MSC 78/6/2 2004).

It should be realised that an approximate approach is being used in the present study. The driving parameters affecting collision or grounding accidents are totally different from each other. As far as each of the parameters affecting collision and grounding is not characterised in a probabilistic form and the related accident scenarios are not identified, it is not feasible to characterise the probabilistic properties of damages. Also, it is important to realise that the raking bottom damage by grounding on a rock with forward speed should be distinguished from the stranding damage case. Despite these approximations, it is still useful to make analysis of both ship accident types by the same methodology and using the same assumptions in order to observe differences in safety levels.

SRA of an Aframax double hull oil tanker is performed using proposed approach. The safety index for intact and damaged ship is determined by employing first-order reliability method (FORM). Sensitivity and parametric analyses are then performed to observe differences in results if input variables are varied within their credible range. This enables identification of the most important parameters on damaged ship safety and consequently relevant conclusions to be drawn. The procedure may have several important practical applications as 
reliability-based comparison of different alternative designs of marine structures in respect of the accidental failure modes, development of new ship structural design rules (Resolution MEPC 110(49) Annex 16 2003; Parunov and Guedes Soares 2008; Xu et al. 2015), as a part of the formal safety assessment procedures (Guedes Soares and Teixeira 2001; MEPC 58 INF.2 2008), for informative decision making in the emergency response actions after accidents (Sun et al. 2014) and in the safety assessment of maritime transportation within sensitive, enclosed and coastal waters (Goerlandt et al. 2012).

\section{Reliability Formulation}

The following limit state function is used, referring to the collapse of the hull girder exposed to the bending moments in the vertical plane:

$\chi_{u} \operatorname{RIF}_{u 0}-\left(K_{U S} M_{S W}+\chi_{w} \chi_{n l} M_{w}\right)<0$

where $M_{u 0}$ is the deterministic ultimate vertical bending moment capacity of the intact ship; RIF is the residual strength index, considered as random variable (for intact ship, RIF = 1); $M_{s w}$ is deterministic still water bending moment for the loading condition considered; $M_{w}$ is the random variable representing extreme vertical wave bending moment corresponding to the rescue period; $K_{U S}$ is the modification factor of the still water load because of the damage $\left(K_{U S}=1\right.$ for the intact ship); $\chi_{u}, \chi_{w}, \chi_{n l}$ are the modelling uncertainty of ultimate bending moment capacity, linear and non-linear wave load, respectively. This is very similar to what was proposed by Guedes Soares et al. (1996) for intact ship, with the modifications associated with the damages.

In Eq. (1), some questions are raised. Collision or grounding accidents may or may not necessarily cause water ingress or oil spills. Subsequently, the still water bending moments may or may not be changed. In this regard, factor $K_{U S}$ may or may not always be different than 1.0. Another aspect that should be considered for damaged ship is the reference level for which reliability is calculated. The ship after damage will only have a voyage of 1 day to 3 weeks to a shipyard for repair. The problem of the exposure time and reference reliabilities is discussed in Parunov et al. (2017b) and Teixeira et al. (2005) in the context of defining probability levels of extreme wave loads for estimation of remaining lifetime of ships. The reliability analysis is herein performed for the sagging failure in full load condition. Reliability indices $\beta$ and associated failure probabilities $P_{f}$ are calculated for the intact ship and for the ship randomly damaged in collision or grounding. In the case of damaged ships, the distinction is made between intact and damaged sections of the ship.

There are several arguments why for damaged oil tanker, only sagging failure mode is considered in full load condition.
Firstly, the risk associated to full load condition is highest because of the most severe consequences of the hull girder failure compared to other loading conditions. Secondly, the oil tanker in full load condition is sailing in still water in the sagging condition and flooding caused by the damage in the midship region tends to further increase the still water sagging bending moment. Finally, most of previous studies indicated that the failure probability of intact double hull oil tanker is highest in sagging and consequently that loading condition is critical for tanker safety. The evidence is MSC IMO document MSC 81/INF.6 (2006) where only sagging failure mode in full load condition is studied.

\section{Grounding and Collision Damages}

The extent of the damage on the ship hull after grounding or collision accidents depends on several parameters such as the speed at contact, contact angle, and mechanical properties of the structures in contact, among others. In this study, however, damage scenarios are considered regardless of the cause of the damage. In grounding and collision damage scenarios, it is assumed that the damaged part of the hull is unable to carry longitudinal stresses and is excluded from the ultimate bending moment computations.

A common way of characterising the extension and location of a damage in the hull is through a 'damage box', i.e. a rectangular parallelepiped with given dimensions in the three directions of space. The damage box was adopted by IMO MEPC to define a probabilistic characterisation of the grounding and collision damage (Resolution MEPC 110(49) Annex 16 2003). The location of the box along the ship is identified in terms of the location, extension and penetration of the damage, which are defined by non-dimensional coordinates, based on the ship main dimensions. In the model suggested by the IMO MEPC, the variables describing the damage box are regarded as independent, and the joint probability density distribution is derived as the product of the five marginal distributions.

The IMO MEPC probabilistic model has some obvious drawbacks (Prestileo et al. 2013). The most important one is that some of the damage boxes extend out of the physical hull boundaries. This occurs when the transverse extent of the damage box is larger than twice the distance between the centre of the box and the ship side or analogously in the longitudinal direction in way of the bow or of the stern. Therefore, a box with centre close to the hull's boundaries in a transverse or longitudinal direction may be partially located out of the hull. In such cases, the real extent of the damage is taken to be smaller than what described by the probabilistic model itself. Consequently, the IMO MEPC model needs to be artificially modified to avoid such unrealistic situations. 
Another limitation of the model is that the damage extent in the three space directions are considered as proportional to the corresponding ship's dimensions, which is not fully supported by simulations and by a detailed analysis of records. Also, the statistics of damage events from the IMO MEPC formulation do not contain information about the type and age of structure of the damaged ships, which is an important element on the resulting damage dimensions. Finally, width, length and height of the damage box are assumed as mutually independent random variables, which is obviously not satisfactory assumption (Parunov et al. 2017a).

The improvement of damage modelling can be done by using numerical simulations including correlation, as exemplified in Parunov et al. (2017a) for collision and Ćorak et al. (2017) for grounding. State of the art in accuracy of numerical simulations is given in Ringsberg et al. (2018).

\subsection{Grounding}

The grounding damage configuration used in many previous studies is defined by the ABS Guidance notes and it includes damage to the bottom shell plating and bottom longitudinal girders but not to the inner bottom plating (American Bureau of Shipping 1995). Harmonized Common Structural Rules (CSR-H) proposes grounding damage much larger than the ABS, which in some cases can penetrate the inner bottom plating (International Association of Classification Societies 2014).

In Paik et al. (2012), IMO MEPC probabilistic damage scenario is improved by introducing the assumption that grounding damage is caused by a conically shaped rock. In such a way, the extent of the damage to the inner bottom plate is less compared to the outer bottom, but both types of damage are still correlated by the shape of the rock. This approach, looking soundly from an engineering point of view, is adopted also in the present study. The approach is further explored in Kim et al. (2013), using the concept of the grounding damage index (GDI). The assumed general damage scenario for grounding caused by conically shaped rock is shown in Figure 1. This model considers a damage box with varying dimensions and location, which are governed, regarding grounding, by the independent probability distribution's expressions (Eqs. (2-6)). The probability density functions of dimensionless size and location of damage box are reproduced from IMO MEPC Resolution MEPC 110(49) Annex 16 (2003) for clarity and completeness of the presentation.

Function for dimensionless transverse location $x_{g 1}$ of centre of the bottom damage relative to the ship's breadth $B$ :

$f_{x g 1}=1.0 ; 0.0 \leq x_{g 1} \leq 1.0$
Function for dimensionless vertical penetration extent $x_{g 2}$ relative to the ship's depth $D$ :

$f_{x g 2}=14.5-134 x_{g 2} ; 0.0 \leq x_{g 2} \leq 0.1$

$f_{x g 2}=1.1 ; 0.1<x_{g 2} \leq 0.3$

Function for dimensionless transverse penetration extent $x_{g 3}$ relative to the ship' breadth $B$ :

$f_{x g 3}=4.0-12 x_{g 3} ; 0.0 \leq x_{g 3} \leq 0.3$

$f_{x g 3}=0.4 ; 0.3<x_{g 3} \leq 0.9$

$f_{x g 3}=12 x_{g 3}-10.4 ; 0.9<x_{g 3} \leq 0.9$

Function for longitudinal location, given as dimensionless distance $x_{g 4}$ from the aft perpendicular relative to the ship's length between perpendiculars $L_{p p}$ :

$f_{x g 4}=0.2+0.8 x_{g 4} ; 0.0 \leq x_{g 4} \leq 0.5$

$f_{x g 4}=4 x_{g 4}-1.4 ; 0.5<x_{g 4} \leq 1.0$

Function for dimensionless longitudinal extent of damage $x_{g 5}$ relative to the ship's length between perpendiculars $L_{p p}$ :

$f_{x g 5}=4.5-13.33 x_{g 5} ; 0.0 \leq x_{g 5} \leq 0.3$

$f_{x g 5}=0.5 ; 0.3<x_{g 5} \leq 0.8$

The random rock angle is assumed as normally distributed random variable with the mean value $\Phi_{\text {mean }}$ given by Eq. (8), and the standard deviation $\sigma$ given by Eq. (9). These expressions imply that $15^{\circ}$ is the minimum rocking angle, while $\Phi_{\max }$, the maximum angle of rock, governed by the geometry of the damage is given by Eq. (7):

$$
\begin{aligned}
& \Phi_{\max }=2 \tan ^{-1} \frac{B x_{g^{3}}}{2 D x_{g^{2}}} ; 15 \leq \Phi_{\max } \leq 150 \\
& \Phi_{\text {mean }}=\frac{15+\Phi_{\max }}{2} \\
& \sigma=\frac{\Phi_{\max }-\Phi_{\text {mean }}}{2}
\end{aligned}
$$

More details of the definition of the geometry of the rocking angle may be found in Paik et al. (2012), Kim et al. (2013) and Bužančić Primorac and Parunov (2015). An efficient method for predicting extent of the bottom damage is presented by Heinvee and Tabri (2015) and subsequently employed for structural reliability assessment of grounded ship by Ćorak et al. (2017).

\subsection{Collision}

A collision with another ship side may result in extensive rupture of the side of the hull structure. ABS Guidelines notes (1995) provide damage levels that are moderate rather than extreme. The collision damage is assumed to be located at upper part of the side shell, 
down from the stringer plate of the strength deck. The inner hull is supposed not to be damaged. CSR-H proposes collision damage larger than the ABS, including damage of the inner shell (International Association of Classification Societies 2014). Like the grounding damage, IMO MEPC adopted the damage box concept to define a probabilistic characterisation of the collision damage (Resolution MEPC 110(49) Annex 16 2003). As it is difficult to establish some more rational correlation between the types of damage to outer and inner shells, the damage box concept is adopted in the present study. The assumed general damage scenario for collision, using the damage box concept is shown in Figure 1. Probabilistic models for collision damage are given as Eqs. (10-14), reproduced herein from IMO MEPC Resolution MEPC 110(49) Annex 16 (2003) for convenience.
Function for dimensionless transverse penetration extent $x_{c l}$, relative to the ship's breadth $B$ :

$$
\begin{aligned}
& f_{x c 1}=24.96-399.2 x_{c 1} ; 0 \leq x_{c 1} \leq 0.05 \\
& f_{x c 1}=9.44-88.8 x_{c 1} ; 0.05<x_{c 1} \leq 0.1 \\
& f_{x c 1}=0.56 ; 0.1<x_{c 1} \leq 0.3
\end{aligned}
$$

Function for non-dimensional vertical penetration extent $x_{c 2}$, relative to the ship's depth $D$ :

$\begin{aligned} f_{x c 2} & =3.83-11.1 x_{c 2} ; 0.0 \leq x_{c 2} \leq 0.3 \\ f_{x c 2} & =0.5 ; 0.3<x_{c 2} \leq 1.0\end{aligned}$

Function for non-dimensional vertical location $x_{c 3}$ of centre of the bottom damage, relative to the ship's depth $D$ :

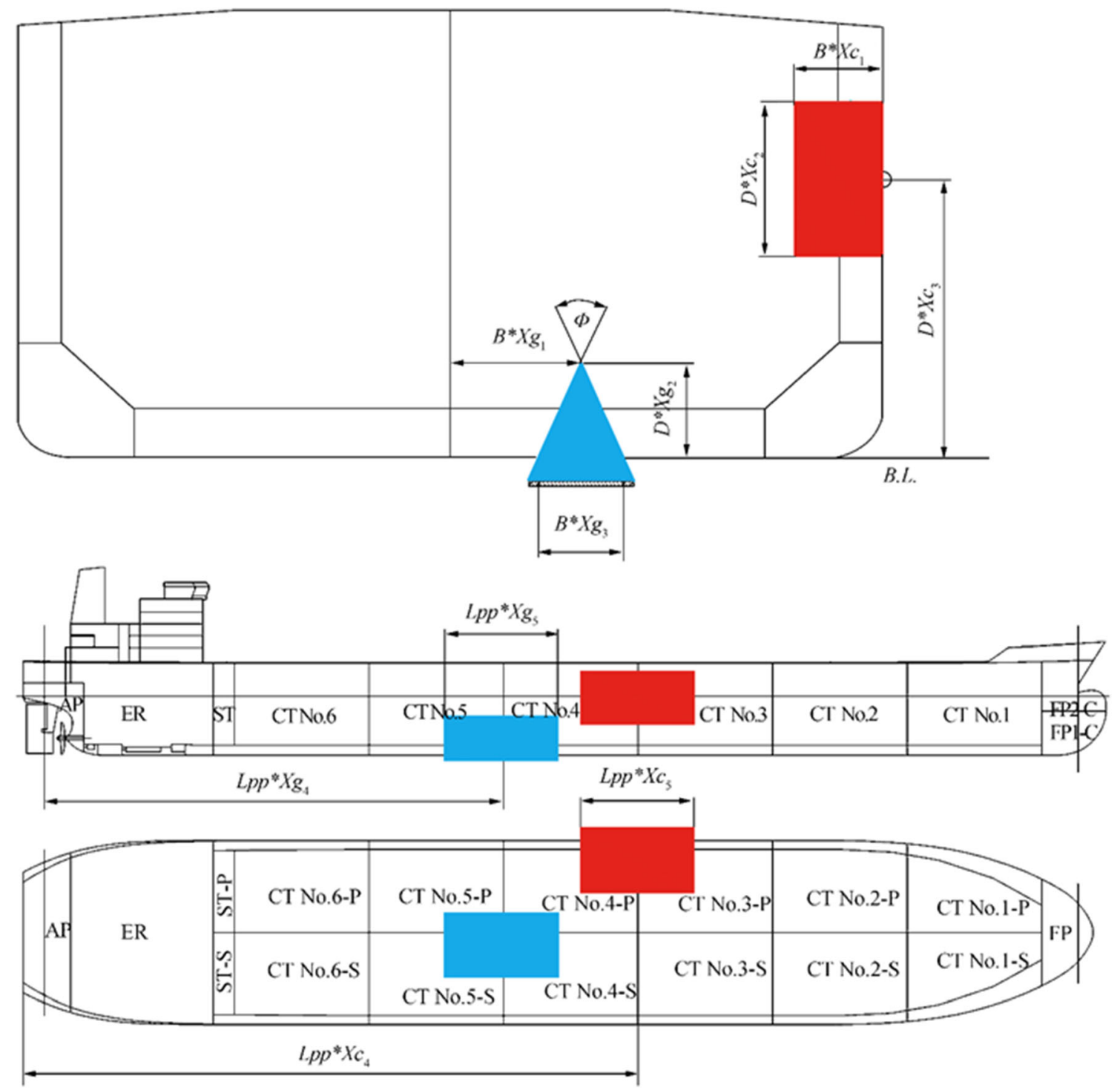

Figure 1 Transverse and longitudinal location and extent of grounding and collision damage 
Table 1 Main particulars of Aframax tanker

Length between perp., LPP (m)

Breadth, $B(\mathrm{~m})$

Deadweight, DWT

Draught, $T(\mathrm{~m})$

$f_{x c 3}=x_{c 3} ; 0.0 \leq x_{c 3} \leq 0.25$

$f_{x c 3}=5 x_{c 3}-1.0 ; 0.25<x_{c 3} \leq 0.5$

$f_{x c 3}=1.50 ; 0.5<x_{c 3} \leq 1.0$

Function for longitudinal location, given as dimensionless distance $x_{c 4}$ from A.P. relative to the ship's length between perpendiculars $L_{p p}$ :

$f_{x c 4}=1.0 ; 0.0 \leq x_{c 4} \leq 0.1$

Function for dimensionless longitudinal extent of damage $x_{c 5}$ relative to the ship's length between perpendiculars $L_{p p}$ :

$f_{x c 5}=11.95-84.5 x_{c 5} ; 0.0 \leq x_{c 5} \leq 0.1$

$f_{x c 5}=6.65-31.5 x_{c 5} ; 0.1<x_{c 5} \leq 0.2$

$f_{x c 5}=0.35 ; 0.2<x_{c 5} \leq 0.3$

Instead of assuming the shape in the form of rectangular box, more realistic assumptions may be done by numerical simulation using explicit FE solvers, as was done, e.g. in Faisal et al. (2017) for random scenarios of collision accidents.

\section{Ship Description}

The ship analysed in the present study is an Aframax double hull oil tanker with main particulars in Table 1, the general arrangement shown in Figure 2 and the midship section in Figure 3. In the longitudinal sense, the cargo tank area is divided into six pairs of oil tanks as well as corresponding pairs of water ballast tanks.

It should be recognised that the reliability associated with hull girder collapsed due to collision and grounding damages must be different depending on the type and size of vessels. The paper considers the Aframax sized oil tanker, but it is not

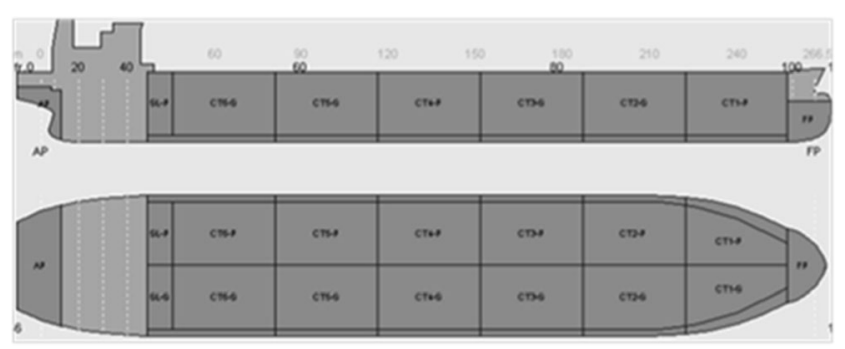

Figure 2 General arrangement of the Aframax tanker

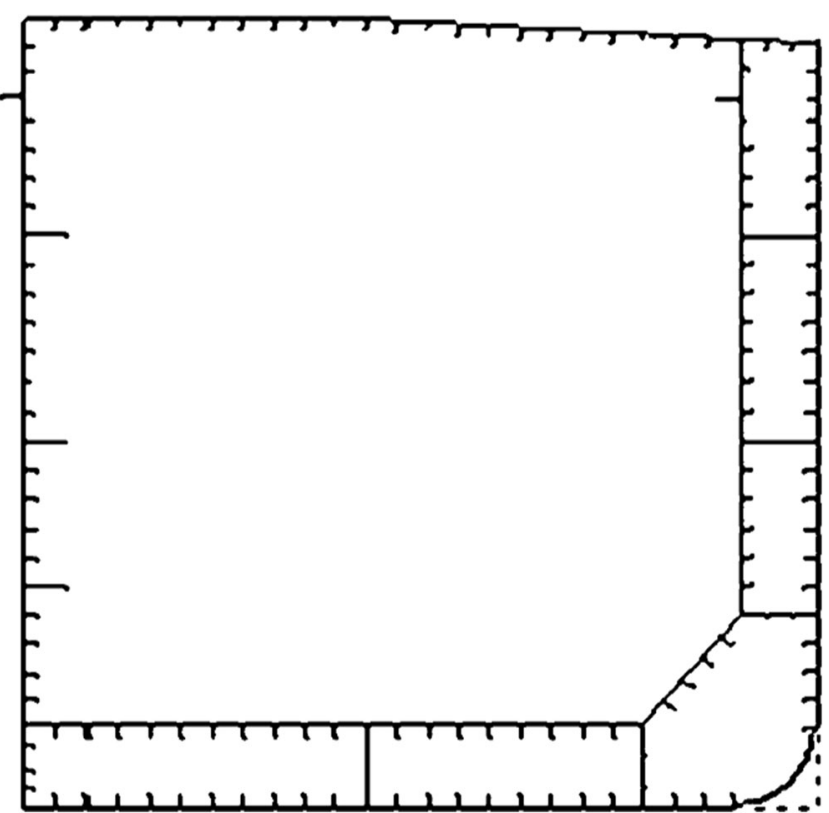

Figure 3 Midship section of the Aframax tanker

relevant to generalise the results of the present study to other sizes, e.g. Suezmax or VLCC class double oil tankers.

\section{Uncertainty Modelling}

\subsection{Ultimate Vertical Bending Moment}

The ultimate hull girder bending moment capacity is defined as the maximum bending moment of the hull girder beyond which the hull will collapse. This moment, generally between the elastic and the plastic moment, is the sum of the contribution of longitudinally effective elements, i.e. the sum of the first moments of the bending stresses around the horizontal neutral axes. According to the literature, the ultimate strength of ship hulls can be predicted using assumed stress distribution methods (Paik et al. 2013), progressive collapse analysis (PCA) method (Gordo and Guedes Soares 1997; Guedes Soares et al. 2008; International Association of Classification Societies 2014), intelligent supersize finite element method (ISFEM) (Magoga and Flockhart 2014) and non-linear finite element methods (Paik et al. 2008).

The PCA method was initially proposed by Smith and represents nowadays the most frequently used method for ultimate strength assessment (Gordo et al. 1996). The crucial part of the Smith's method is to develop a stress-strain relationship for beam columns, of which stiffened panels forming the ship hull are composed. Stress-strain relationships most often used nowadays are those proposed in CSR-H (International Association of Classification Societies 2014). The ultimate bending moment is then calculated by an incrementally iterative procedure. The ultimate bending moment capacity of 
intact ship in sagging used in the present study (Figure 3) using PCA reads $8470 \mathrm{MNm}$.

Similar methods as for the intact ship are found in literature for calculation of the residual strength of damaged ship hulls (Youssef et al. 2016). The approach generally adopted considers that the elements within the damaged area are removed and the ultimate strength of the ship is recalculated using the simplified methods. The results of a benchmark study are reported in Guedes Soares et al. (2008) in which the strength of a damaged ship hull was calculated with 3D nonlinear finite elements and was compared with the strength predicted by various codes based on the Smith method showing in general a good correlation.

One specific problem appearing for collision damage is that when the cross-section is asymmetrically damaged, the neutral axis rotates and the problem needs to be treated as biaxial bending problem, even if the loading is in the vertical plane only. Recently, a PCA method by a pure incremental method was developed (Muhammad Zubair 2013) to derive the biaxial bending moment-curvature relationship considering the rotation and translation of the neutral axis in asymmetrically damaged hull girders. The method is subsequently utilised in Makouei et al. (2015) to develop several design formulas to predict residual strength of a ship in a damaged condition.

In the present study, ultimate strength calculations in sagging are performed by using the modified Paik-Mansour method (Paik et al. 2013). The method is an extension of the original Paik-Mansour ( $\mathrm{P}-\mathrm{M})$ method, which is based on the assumed stress distribution over the hull cross-section at the ultimate limit state in sagging (Paik and Mansour 1995), i.e. yield stress $\sigma_{x}^{y}$ is assumed for the outer bottom panel and ultimate stress $\sigma_{x}^{u}$ for the deck panel together with vertical structural elements. The modified $\mathrm{P}-\mathrm{M}$ method assumes different bending stress distributions at the ultimate limit state for the yielded area, i.e. the vertical structure elements close to the tension flange may also have yielded before the hull girder reaches the ultimate limit state. The modified method involves two unknowns, i.e. the height of the buckled element region $\left(h_{C}\right)$ and the height of the yielded element region $\left(h_{Y}\right)$. The condition that the summation of axial forces over the entire cross-section of the hull under a vertical bending moment becomes zero is insufficient to determine two unknowns, and thus an iteration process is required to determine the heights $h_{C}$ and $h_{Y}$. The method is considered as very practical for conceptual studies like the present one and useful for definition of design equations as recommended by ISSC (Committee III.1 2015a, b). For comparison, the ultimate bending moment for the subject tanker in sagging, calculated using modified $\mathrm{P}-\mathrm{M}$ method reads $8744 \mathrm{MNm}$, being 3\% higher compared to the result of the PCA analysis.

The modified $\mathrm{P}-\mathrm{M}$ method does not consider the rotation of the neutral axis, so this effect is separately considered by the correction (Eq. (15)) defined by Muhammad Zubair (2013):

$\frac{M_{V}^{u}}{\left.M_{V}^{u}\right|_{C A S E 2}}=\frac{I_{H H} I_{V V}-I_{H V}^{2}}{-\left(y_{C}-y_{G}\right) I_{H V}+\left(z_{C}-z_{G}\right) I_{H H}} \frac{\left(z_{C}-z_{G}\right)}{I_{V V}}$

where $y_{C}, z_{C}$ are the location of the critical member on the ship main deck (main deck at CL); $y_{G}, z_{G}$ are the centroid coordinates of the damaged cross-section; $I_{V V}$ is the axial moment of inertia (vertical) of the damaged cross-section relating axis $y ; I_{H H}$ is the axial moment of inertia (horizontal) of the damaged cross-section relating axis $z$; $I_{H V}$ is the centrifugal moment of inertia of the damaged cross-section relating $y$ - and $z$-axes; $M_{V}^{u}$ is the residual vertical hull girder strength in sagging including effect of rotation of NA; $\left.M_{V}^{u}\right|_{C A S E 2}$ is the residual vertical hull girder strength in sagging without rotation of NA.

It should be noted that one of the conclusions by Muhammad Zubair (2013) is that the reduction ratio of the residual hull girder strength due to the rotation of the neutral axis is almost negligible for the case of oil tankers having suffered outer shell damage. Therefore, in most of the cases, the effect of the rotation of the neutral axis will not have significant influence. Correction by Eq. (15) for rotation of neutral axis has the effect of reducing ultimate longitudinal strength in sagging by up to $7 \%$. The overall accuracy of the $\mathrm{P}-\mathrm{M}$ method and the Eq. (15) is confirmed by the non-linear FEM analysis, performed by Parunov et al. (2017c).

For CSR-H collision damage (damage height equal to $60 \%$ of ship depth, outer and inner shell damaged), loss of bending moment capacity in sagging reads $16 \%$ and $20.5 \%$, for the case without and with rotation of the neutral axis, respectively. For CSR-H grounding damage (damage breadth equal to $60 \%$ of ship breadth, only outer bottom damaged), the loss of the sagging ultimate bending moment reads $17.5 \%$.

The random reduction of the ultimate bending moment for the ship damaged by grounding or collision is calculated by Monte Carlo (MC) simulation, assuming that the damage parameters are random variables described by probability density functions proposed by IMO Resolution MEPC 110(49) Annex 16 (2003). A data set of 1000 random grounding and collision damage scenarios are simulated. For each set of damage parameters generated by $\mathrm{MC}$ simulation, residual ultimate strength is calculated using the modified $\mathrm{P}-\mathrm{M}$ method with correction according to Eq. (15).

The random loss of the ultimate bending capacity of damaged ship $\left(M_{u \text { loss } \%}\right)$ is expressed as the percentage of the residual ultimate hull girder bending moment of the damaged ship $\left(M_{u D}\right)$ with respect to the ultimate hull girder bending moment of the intact ship $\left(M_{u 0}\right)$ as:

$M_{u \operatorname{loss} \%}=\left(1-\frac{M_{u D}}{M_{u 0}}\right) \cdot 100$ 
$M_{u \text { loss\% }}$ may be reasonably represented by the exponential distribution, while parameters of the distributions are given in Table 2 and the related histograms with fitted exponential functions are shown in Figure $4 \mathrm{a}$ and $\mathrm{b}$, for grounding and collision damage, respectively. Several different MC simulations have been repeated resulting always in similar mean value and standard deviation of the resulting histogram, proving that the presented procedure is stable.

As the fitted distributions represent the random variable loss of ultimate bending moment, the residual strength index (RIF), appearing in Eq. (1), is also a random variable expressed as function of relative loss of ultimate bending moment (Eq. (17)) as:

$\mathrm{RIF}=\frac{M_{u D}}{M_{u 0}}=1-\frac{M_{u \text { loss } \%}}{100}$

This expression for RIF is therefore eventually included in the limit state function (Eq. (1)).

According to the probability distribution presented in Figure 4, the probability of the loss of ultimate strength caused by CSR-H damage is about $1.5 \%$ and $0.5 \%$ for grounding and collision, respectively.

In several reliability analyses, the ultimate bending strength, calculated by the deterministic methods based on the characteristic values of the material and of the geometrical parameters of the hull girder, has been considered to be the expected value of the ultimate strength of the midship section and all uncertainty are typically concentrated in a model uncertainty random variable $\chi_{u}$. A log-normal distribution is usually selected to describe this model uncertainty. It considers both the uncertainty in the yield strength and the model uncertainty of the method to assess the ultimate capacity of the midship section. The uncertainty associated with the predictions of the simplified methods used to calculate the hull girder ultimate strength can be assessed by comparing the results obtained by different methods. For this purpose, different simplified progressive collapse methods developed by several organisations have been used to calculate the ultimate bending strength of a RoRo vessel in the project MARSTRUCT (Teixeira et al. 2011). The results obtained showed that the coefficient of variation of the predictions is larger in the sagging condition than in hogging. This study gave an idea of the range of variation of the predictions of the various methods that can be incorporated in

Table 2 Parameters of distribution for random loss of sagging UBM (\%)

\begin{tabular}{lll}
\hline Damage & Distribution & Mean \\
\hline Grounding & exponential & 4.160 \\
Collision & exponential & 3.587 \\
\hline
\end{tabular}

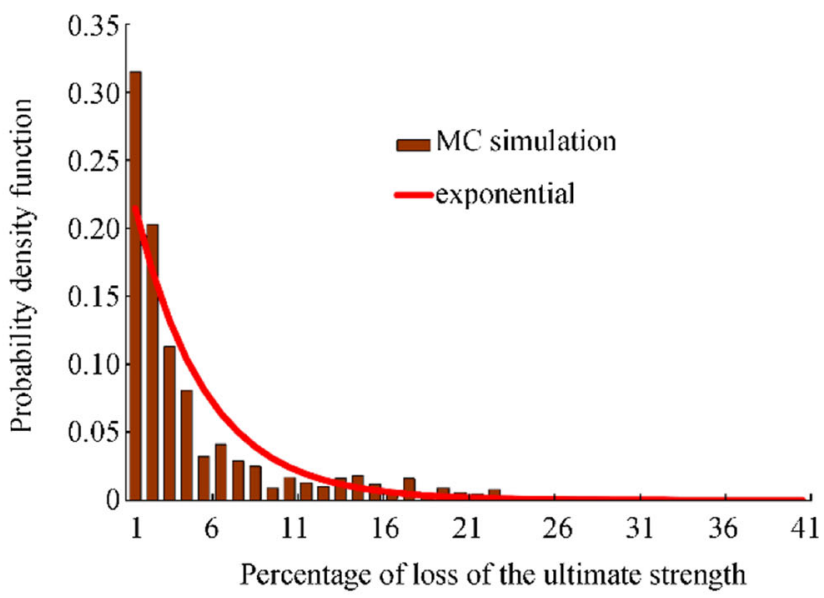

(a) Grounding damage $(\bar{x}=4.160)$

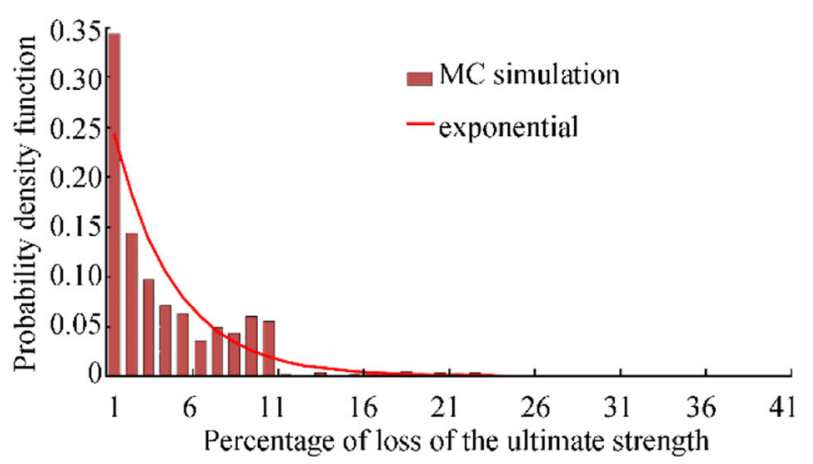

(b) Collision damage $(\bar{x}=3.587)$

Figure 4 Histograms of losses of the ultimate strength in sagging with fitted exponential function

the reliability formulations by an additional model uncertainty random variable affecting the stochastic model of the ultimate strength of the hull girder. Since the coefficient of variation of the yield strength of the steel normally ranges from $8 \%$ to $10 \%$ it has been assumed that the additional model uncertainty will bring the overall coefficient of variation to $12 \%$, while the mean value is equal to 1.1. This bias is caused by using the characteristic material yield strength in the analysis instead of its mean value (Teixeira et al. 2011; Parunov and Guedes Soares 2008).

\subsection{Still Water Bending Moment}

SWBM at midship section for an intact ship in full load condition reads $1819 \mathrm{MNm}$, where negative sign denotes sagging. For a damaged ship, SWBM is multiplied by the random factor $K_{U S}$, representing change of SWBM because of the damage.

Random damage scenarios are generated by Monte Carlo simulation using IMO probability distributions of damage parameters (Resolution MEPC 110(49) Annex 16 2003). Following the procedure described in Section 2, 1000 random numbers are 
drawn according to IMO models. Basically, each outcome of the random number generation creates flooding of some compartments and bending moment distribution is then calculated by commercial hydrostatic software. Distinction is made between maximum $\mathrm{SWBM}_{\mathrm{d}}$ in damaged condition along whole ship and maximum value in the region of damaged tanks only.

One example of calculated SWBM distribution is shown in Figure 5. A large increase of SWBM in the damaged condition, not only in respect of SWBM of intact ship but also beyond permissible seagoing SWBM may be noticed in Figure 5.

It should be clarified that the damage of water ballast tanks at amidships represents the severest case regarding increase of SWBM, while in most other damage scenarios, the increase of SWBM is not so large. In many of damage cases, SWBM decreases in respect of the intact condition.

Histograms of relative SWBM in damaged condition are presented in Figures 6 and 7 for collision and grounding damages, respectively. Relative SWBM is a random factor $K_{U S}$ of change of SWBM appearing in Eq. (1) and represents the ratio of $\mathrm{SWBM}_{\mathrm{d}}$ in damaged condition and $\mathrm{SWBM}_{\mathrm{i}}$ for intact ship. The random $K_{U S}$ may be reasonably fitted with the normal distribution. Parameters of the normal distributions are given in Table 3. Comparison of histograms and normal distribution are also shown in Figures 6 and 7. Details of the damage stability calculations may be found in Bužančić Primorac et al. $(2015 a, b)$ for the case of Aframax and Suezmax tanker, respectively.

Some simplifications are assumed in the present study, as collision or grounding accidents do not necessarily cause water ingress or oil spills. Subsequently, the still water bending moments may or may not be changed. However, it is
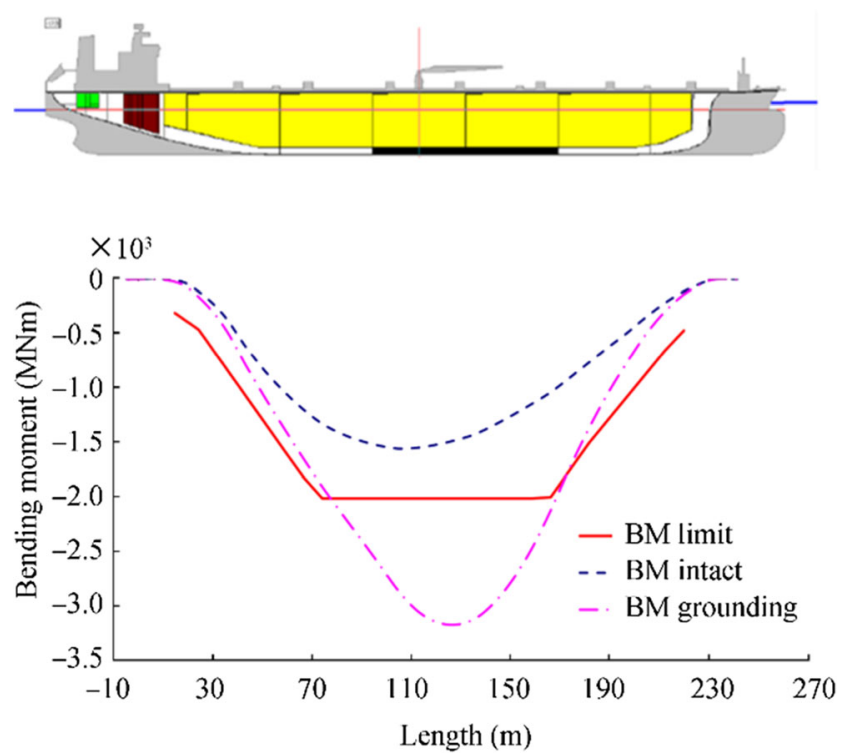

Figure 5 Comparison of SWBM diagrams for intact ship and for ship after grounding damage of WBT 3-4P\&S

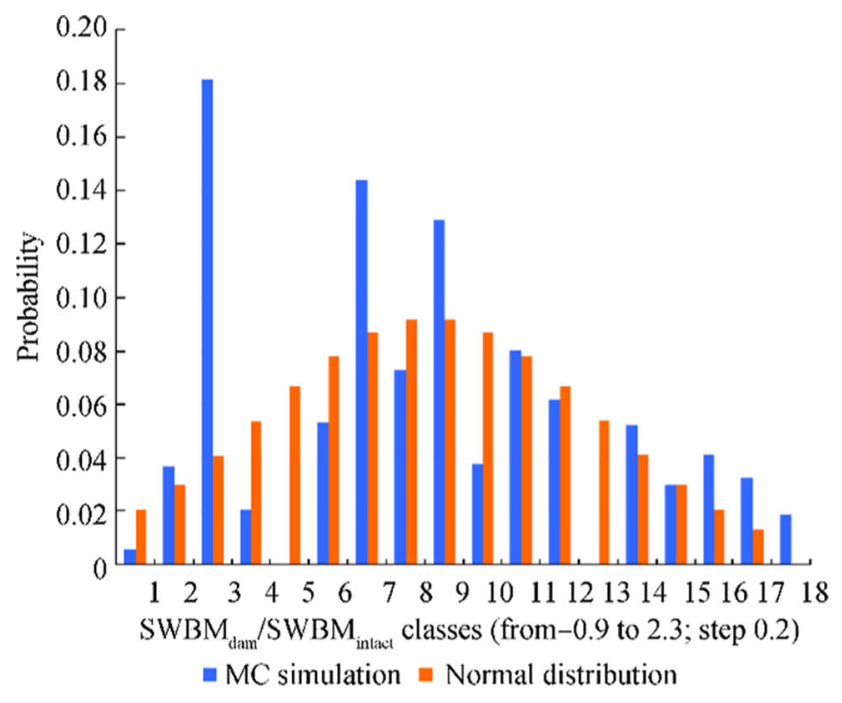

(a) Overall maximum $K_{U S}$

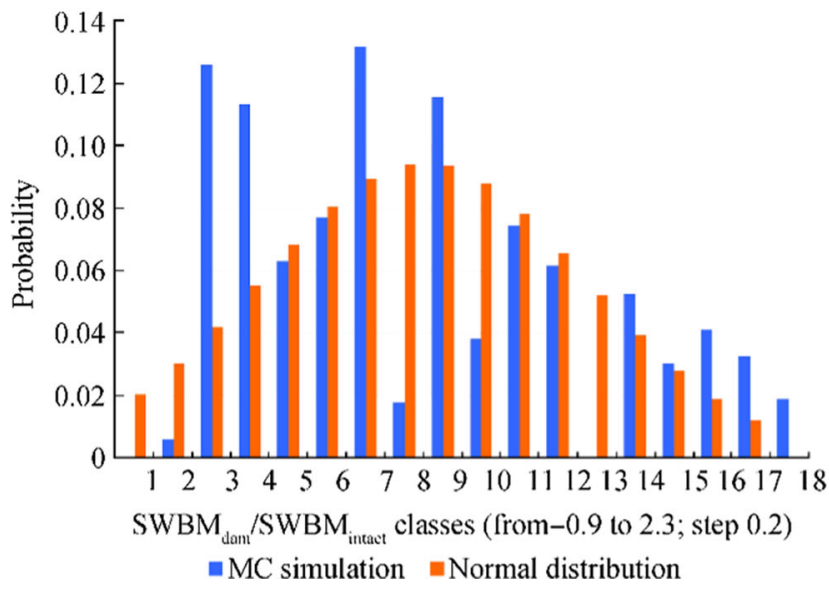

(b) Maximum $K_{U S}$ in the area of damaged tanks

Figure 6 Histograms and normal distributions of $K_{U S}$ after grounding damage

simplistically assumed in the present study that each damage causes flooding of the compartments in the damaged region.

\subsection{Vertical Wave Bending Moment}

Calculations of transfer functions of vertical wave bending moment for damaged ships are described in Parunov et al. (2015) and Folsø et al. (2008) by applying linear hydrodynamic methods, while experiments on damaged ships are performed in Lee et al. (2012), Begovic et al. (2011, 2013, 2017) and Ćatipović et al. (2019). Assessment of consequences of damage on transfer functions of ship motions and global wave-induced loads are given by Mikulić et al. (2018), whereas benchmark study of global wave loads on damaged ship is presented by Parunov et al. (2020). Generally, global wave loads on damaged ship are lower compared to the intact condition (Hirdaris et al. 2014). Thus, the IACS CSR-H (International Association 


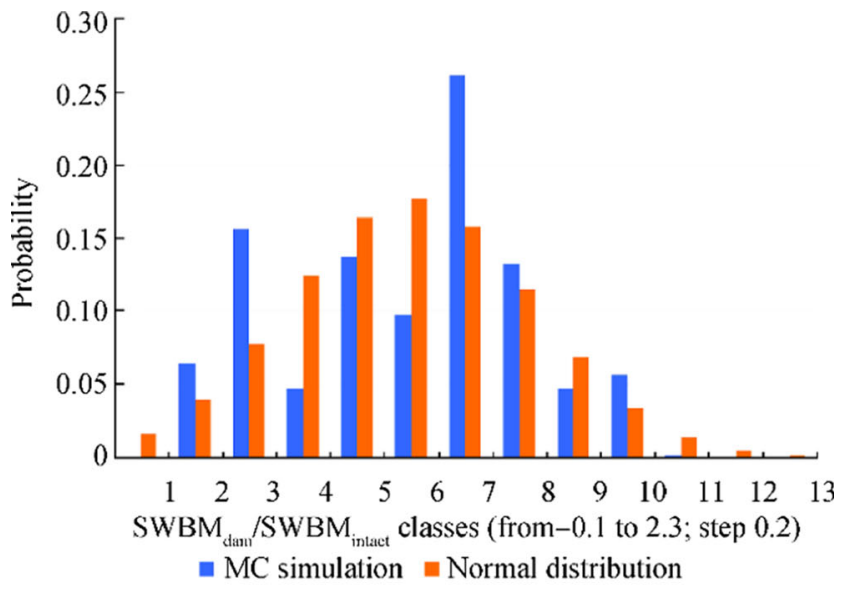

(a) Overall maximum $K_{U S}$

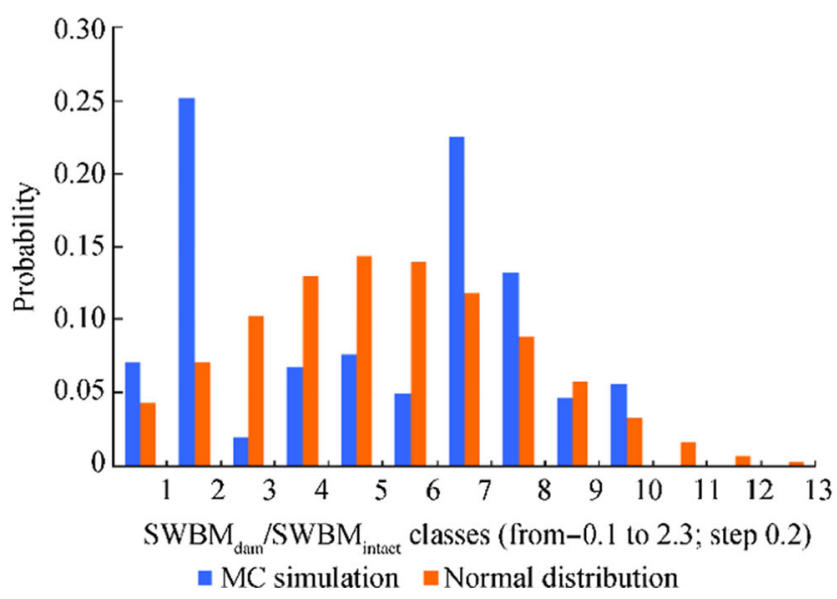

(b) Maximum $K_{U S}$ in the area of damaged tanks

Figure 7 Histograms and normal distributions of $K_{U S}$ after collision damage

of Classification Societies 2014) are aimed at checking the hull girder ultimate bending capacity in the damaged state using partial safety factor for wave loads of 0.67 , while in the intact condition, this factor reads 1.1 .

The wave loads of damaged ship are determined based on the wave condition (e.g. significant wave height and wave length) at the moment of accident in sea together with the small vessel speed in association with exposure time of couple of days during the rescue operation. Collision environment is normally milder than the open seas in the North Atlantic, as

Table 3 Parameters of distributions of $K_{U S}$ for damaged ship

\begin{tabular}{lll}
\hline Damage condition & Mean value & Standard deviation \\
\hline Collision (overall) & 0.88 & 0.45 \\
Collision (damaged area) & 0.76 & 0.55 \\
Grounding (overall) & 0.60 & 0.86 \\
Grounding (damaged area) & 0.58 & 0.85 \\
\hline
\end{tabular}

around $88.8 \%$ collisions happened in harbour or coastal waters. Jia and Moan (2008) presented the sea states at the time of collisions from the HARDER project, which are used in the present study. 2P Weibull probability distribution of peaks of wave bending moment is calculated herein by computer programme developed by Jensen and Mansour (2002), using closed-form expressions of response amplitude operators (RAOs) for the intact ship. Probability distribution is obtained by assuming HARDER wave scatter diagram, head seas and small forward speed of 5 knots. Long-term distribution of the wave-induced vertical bending moments of the intact ship was carried out for sea areas in the North Atlantic in accordance with the IACS Recommendation Note No. 34 (2000).

The probability that the random amplitude of vertical wave bending moments (VWBM) remains less than a given value $x_{\mathrm{e}}$ over a time period, e.g. 1 voyage, 1 year or 20 years, is given by the Gumbel law:

$F\left(x_{e}\right)=e^{-e^{\left(-\left(x_{e}-x_{e}^{*} / \alpha\right)\right)}}$

where parameters $x_{e}^{*}$ and $\alpha$ are derived from the scale parameter $\theta$ and the shape parameter $\lambda$ of the Weibull distribution, which is an excellent approximation of the amplitude of various ship responses in waves, by following relationships:

$\alpha=\frac{\theta}{\lambda}(\ln n)^{(1-\lambda) / \lambda}$

$x_{e}^{*}=\theta(\ln n)^{1 / \lambda}$

where $n$ is the number of response cycles in a given long-term period, while $x_{e}^{*}$ is the most probable extreme value in $n$ cycles.

The mean value $\mu_{W E}$ and standard deviation $\sigma_{W E}$ of the Gumbel distribution are then given as

$\mu_{W E}=M_{W E}^{*}+\alpha \cdot 0.5772$

$\sigma_{W E}=\frac{\pi}{\sqrt{6}} \alpha$

The Gumbel distribution obtained by this procedure is the inherent uncertainty of the extreme vertical wave bending moment, as represented by the random variable $M_{w}$ in Eq. (1). The Gumbel moments of the extreme vertical wave-induced bending moment for the full load condition for intact and damaged ship is described in Table 4. Exposure time of 1 year in the North Atlantic is assumed for intact ship, while exposure time of 1 week in

Table 4 Gumbel moments of extreme vertical wave bending moment (MNm)

\begin{tabular}{lllllll}
\hline 1 year in North Atlantic & & & \multicolumn{2}{l}{1 week in 'collision environment' } \\
\cline { 1 - 1 } \cline { 5 - 7 }$n$ & $\mu_{e}$ & $\sigma_{e}$ & & $n$ & $\mu_{e}$ & $\sigma_{e}$ \\
\hline $3.94 \times 10^{6}$ & 3723 & 314 & 74000 & 3348 & 552 \\
\hline
\end{tabular}


Table 5 Summary of stochastic model adopted

\begin{tabular}{|c|c|c|c|c|c|}
\hline Variable & Damage & Distribution & & Mean & $\mathrm{COV}$ \\
\hline$M_{u}(\mathrm{MNm})$ & Intact & Deterministic & $\begin{array}{l}\text { 'as-built' } \\
\text { 'corroded' }\end{array}$ & $\begin{array}{l}8246 \\
6813\end{array}$ & \\
\hline$M_{u \mathrm{loss}} \%$ & $\begin{array}{l}\text { Collision } \\
\text { Grounding }\end{array}$ & $\begin{array}{l}\text { Exponential } \\
\text { Exponential }\end{array}$ & & $\begin{array}{l}0.036 \\
0.042\end{array}$ & \\
\hline$M_{s w}(\mathrm{MNm})$ & Intact & Deterministic & & $1556(\mathrm{sag})$ & \\
\hline$M_{w, \text { intact }}(\mathrm{MNm})$ & Intact & Gumbel & & 3723 & 0.08 \\
\hline$M_{w, \text { damaged }}(\mathrm{MNm})$ & Collision and grounding & Gumbel & & 3348 & 0.16 \\
\hline \multirow[t]{4}{*}{$K_{U S}$} & Collision (overall) & Gaussian & & 0.88 & 0.51 \\
\hline & Collision (damaged area) & & & 0.76 & 0.72 \\
\hline & Grounding (overall) & & & 0.60 & 1.43 \\
\hline & Grounding (damaged area) & & & 0.58 & 1.47 \\
\hline$\chi_{u}$ & & Log-normal & & 1.1 & 0.12 \\
\hline$\chi_{w}$ & & Gaussian & & 1.0 & 0.1 \\
\hline$\chi_{n l}$ & & Gaussian & & 1.03 & 0.15 \\
\hline
\end{tabular}

HARDER collision wave environment is assumed for damaged ship.

Simplifications, assumptions and inaccuracies of the linear engineering models used to predict extreme VWBM on ship hull are considered by the modelling uncertainty $\chi_{w}$, which appears in Eq. (1). For the present study, $\chi_{w}$ is assumed to be a normally distributed random variable with the mean value equal to 1 and coefficient of variation equal to 0.1 . The effect of the non-linearity of the response is particularly significant for ships with a low block coefficient, leading to differences between sagging and hogging bending moments. The uncertainty of nonlinear effects $\chi_{n l}$ is assumed to be a normally distributed variable with mean value equal to non-linear correction factors proposed by IACS UR S11, while the coefficient of variation of this uncertainty is assumed to be 0.15 (International Maritime Organisation 2006).

\section{Results of the Reliability Analysis}

The safety indices conditional upon the occurrence of sudden damage are calculated using the FORM method. The summary of the stochastic models adopted for random variables and the deterministic values is presented in Table 5. The analysis is performed for 'as-built' state and also for 'corroded' state, where structural elements are corroded according to the corrosion wastage specified in Common Structural Rules for Double Hull Oil Tankers (CSR-OT 2006). It should be clarified that the only degrading effect of corrosion is that of the uniform thickness reduction. Other ageing effects as non-uniform corrosion (e.g. pitting and grooving) and fatigue cracking are not considered in the present paper.
FORM is usually used in this type of conceptual studies, and most results in the literature show that no significant improvement could be achieved by using SORM method. MC simulation could have been used and it would certainly change slightly the numerical values of the reliability index obtained. However, it would not change the relative values between the various cases considered and thus would not change the conclusions. Considerations about the degree of accuracy of the various methods are outside the scope of the present study.

\subsection{Safety Indices and Failure Probabilities}

Reliability indices $\beta$ and associated failure probabilities $P_{f}$ are calculated for the sagging failure mode and for full load condition. The calculated values for intact ship and for intact and damaged section of the ship damaged by collision and grounding are presented in Tables 6 and 7 for 'as-built' and 'corroded' state, respectively. For the intact area of the damaged ship, it is assumed that only global hull girder loading is changed because of the effects of the damage, while the cross-sectional properties, including ultimate longitudinal strength, are unchanged in respect of the intact vessel. Therefore, RIF $=1$

Table 6 Safety indices and failure probabilities for intact and damaged ship ('as-built' ship)

\begin{tabular}{lll}
\hline Damage condition & $\beta$ & $P_{f}$ \\
\hline Intact & 2.83 & $2.34 \mathrm{E}-03$ \\
Collision (intact area) & 2.67 & $3.76 \mathrm{E}-03$ \\
Collision (damaged area) & 2.56 & $5.31 \mathrm{E}-03$ \\
Grounding (intact area) & 2.45 & $7.08 \mathrm{E}-03$ \\
Grounding (damaged area) & 2.34 & $9.63 \mathrm{E}-03$ \\
\hline
\end{tabular}


Table 7 Safety indices and failure probabilities for intact and damaged ship ('corroded' ship)

\begin{tabular}{lll}
\hline Damage condition & $\beta$ & $P_{f}$ \\
\hline Intact & 1.81 & $3.52 \mathrm{E}-02$ \\
Collision (intact area) & 1.88 & $3.02 \mathrm{E}-02$ \\
Collision (damaged area) & 1.79 & $3.69 \mathrm{E}-02$ \\
Grounding (intact area) & 1.73 & $4.15 \mathrm{E}-02$ \\
Grounding (damaged area) & 1.64 & $5.05 \mathrm{E}-02$ \\
\hline
\end{tabular}

for intact region of the damaged ship, while overall values from Table 5 are assumed for $K_{U S}$.

It may be seen from Tables 6 and 7 that the reliability indices of damaged ships are in general slightly lower than for the intact ship. The reliability index for grounding is lower than for collision. Also, the reliability index for the damaged area is lower compared to the intact region of damaged ship. This is even though SWBM model employed for intact area is more severe compared to the damaged area (see Table 3).

Furthermore, an interesting finding from Tables 6 and 7 is that for 'corroded' state, differences between safety indices for damaged and intact ship are lower compared to the 'as-built' state of the structure. For the case of the intact area of a ship damaged by collision, the reliability index is even higher for the damaged condition. The reason is that the corrosion wastage has larger influence on the structural safety compared to the load effects of the sudden collision damage.

Failure probabilities of the damaged ship are conditional values and should be multiplied by the probability that collision or grounding occurs. There are different sources of statistical data about ship accidents. Thus, IMO MEPC Resolution MEPC 110(49) Annex 16 (2003) provides yearly frequencies of $1.40 \mathrm{E}-02$ and $7.49 \mathrm{E}-03$ for collision/contact and grounding, respectively. Unconditional failure probabilities for collision and grounding are hence about two orders of magnitude lower compared to values specified in Tables 6 and 7 .

\subsection{Sensitivity Analysis}

Sensitivity analysis is performed by calculating the normalised sensitivity factors $\alpha_{i}$, which are presented in Tables 8,9 and 10 and in Figures 8, 9 and 10.

In the same tables, the coordinates of the design point $x_{\mathrm{i}}^{*}$, representing the most probable combination of random

Table 8 Sensitivity factors $\alpha$ and coordinates of design point $x^{*}$ for intact ship

\begin{tabular}{lllll}
\hline & $\chi_{u}$ & $\chi_{w}$ & $\chi_{n l}$ & $M_{w}$ \\
\hline$\alpha_{i}(\%)$ & 32.0 & 19.0 & 25.9 & 23.1 \\
$x_{i}^{*}$ & 0.87 & 1.11 & 1.25 & 4105 \\
\hline
\end{tabular}

Table 9 Sensitivity factors $\alpha$ and coordinates of design point $x^{*}$ for ship damaged by collision (damaged area)

\begin{tabular}{lllllll}
\hline & $\chi_{u}$ & $\chi_{w}$ & $\chi_{n l}$ & $M_{w}$ & $M_{u \text { loss } \%}$ & $K_{U S}$ \\
\hline$\alpha_{i}(\%)$ & 20.7 & 11.5 & 16.1 & 24.8 & 7.0 & 19.8 \\
$x_{i}^{*}$ & 0.94 & 1.07 & 1.18 & 4131 & 0.05 & 1.40 \\
\hline
\end{tabular}

variables in the case of failure, are included. Sensitivity analysis is performed for 'as-built' state only.

From Table 8, it follows that VWBM is overall the most important random variable for the intact ship. The random variables related to the $\operatorname{VWBM}\left(\chi_{w}, \chi_{n l}\right.$ and $\left.M_{w}\right)$ contribute together $68 \%$ to the total variability. Individually, however the uncertainty of ultimate bending capacity is the highest.

It may be seen from Tables 9 and 10, that for the damaged oil tanker variable $K_{U S}$, representing change of SWBM because of the flooding becomes also an important random variable. This is especially the case for the grounding, where $K_{U S}$ is individually the most important random variable.

It is also interesting to analyse results for design points, presented in Tables 9 and 10. At failure, it is likely that the factor of increase of SWBM, $K_{U S}$, will take value of 1.40 and 1.89 for collision and grounding, respectively. This is another evidence of the tremendous importance of SWBM after flooding on structural safety of a damaged oil tanker. Loss of the ultimate strength at failure reads $5 \%$ and $6 \%$ for collision and grounding, respectively.

\subsection{Parametric Study}

A parametric study is performed for sagging failure mode of the damaged ship in 'as-built' state. This is done to get better insight into the sensitivity of the procedure to the input parameters. The variation of two parameters is performed; $M_{u l o s s} \%$ is the random loss of the ultimate bending capacity of damaged ship and $K_{U S}$ is the random change of the still water load of damaged ship. Only one of the parameters is varied in each reliability analysis, while another retains its 'best estimate' as specified in Table 5. The parameters' interval limits are calculated for the corresponding mean values $\bar{x}$ of $M_{u \text { loss } \%}$ and $K_{U S}$ for collision and grounding damage, respectively, as the

Table 10 Sensitivity factors $\alpha$ and coordinates of design point $x^{*}$ for ship damaged by grounding (damaged area)

\begin{tabular}{lllllll}
\hline$\chi_{u}$ & $\chi_{w}$ & $\chi_{n l}$ & $M_{w}$ & $M_{u \text { loss } \%}$ & $K_{U S}$ & \\
\hline$\alpha_{i}(\%)$ & 20.1 & 9.8 & 13.9 & 19.1 & 7.9 & 29.3 \\
$x_{i}^{*}$ & 0.96 & 1.05 & 1.14 & 3887 & 0.06 & 1.89 \\
\hline
\end{tabular}


Intact

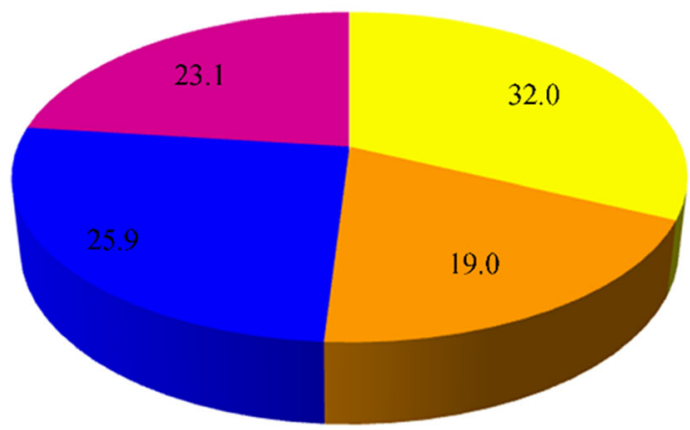

Figure 8 Sensitivity factors for intact ship

95\% confidence interval by the conventional approach (central limit theorem).

The results of the parametric study are presented in Tables 11 and 12. It may be seen that the variation of the $M_{u \text { loss\% }}$ results in lower variability of the safety indices, compared to the variation of the $K_{U S}$. Also, comparing the values for safety indices from Table 12, it can be concluded that the variation of $K_{U S}$ gives somewhat higher variability for ship damaged by grounding than for the collision damage.

One of the useful applications of ship structural reliability analysis is the rule development process. The present oil tanker is pre-CSR design. Reinforcements according to CSR-OT (2006) lead to an increase of the ultimate bending moment to $9078 \mathrm{MNm}$ and $7587 \mathrm{MNm}$ for 'as-built' and 'corroded' states, respectively. Results of the reliability analyses for intact and damaged CSR ship for 'as-built' and 'corroded' state are shown in Tables 13 and 14.

Results of the reliability analysis are summarised in Figure 11, where safety indices for intact and damaged ship are compared including their parametric variation within a reasonable range. Figure 11 includes results for the 'as-built' and 'corroded' ships. It is interesting to observe from Figure 11 that the safety index of a ship damaged by random collision damage is slightly lower compared to the intact ship. However, for random grounding damage, the safety index is much reduced and noticeably lower. Positive impact of CSR

Collision-damaged section

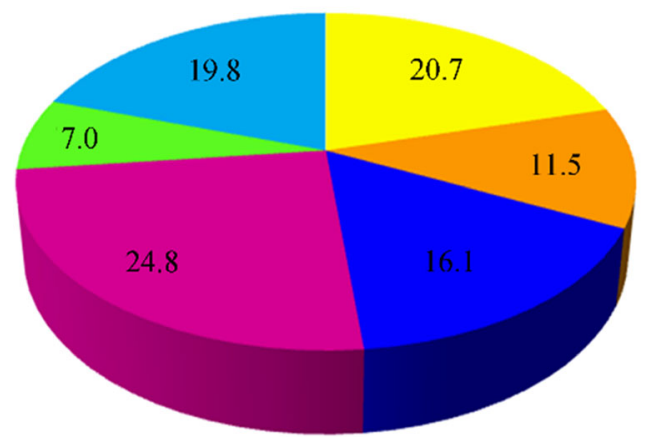

Figure 9 Sensitivity factors for collision (damaged area)

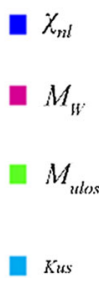

Grounding-damaged section

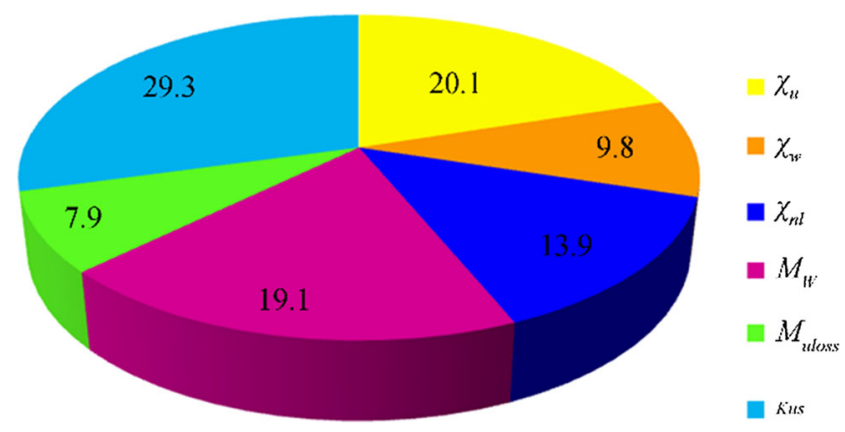

Figure 10 Sensitivity factors for grounding (damaged area)

on structural safety of both intact and damaged ship is clearly seen in Figure 11.

\section{Discussion}

It is interesting to compare the obtained results to the other similar studies. Failure probabilities in Table 6 for grounding are between values calculated in Prestileo et al. (2013) of 1.785E-02 and 5.419E-04 for similar ship using Bayesian networks. Failure probabilities calculated in Downes et al. (2007) for different damage scenarios of Aframax tanker read between $8.95 \mathrm{E}-03$ and $1.09 \mathrm{E}-03$. The values presented in Table 6 are in good agreement with those probabilities. Therefore, one may conclude that the obtained results are reasonable and in good agreement with other similar researches.

The effect of corrosion is studied in the conventional way, by removing the 'rule' corrosion addition from 'as-built' thickness. It is shown that the relative decrease of the safety index of a damaged ship in respect of the safety index of the intact structure is much higher for the 'as-built' state compared to the 'corroded' state.

It is also demonstrated how the presented procedure may be employed in the rule development process. Effects of structural modifications because of the application of new rules may be evaluated in terms of safety after accidental damage using the procedure presented in the present paper. Such approach can stimulate innovation in the structural

Table 11 Safety indices for various mean values of $M_{u \text { loss } \% \text { for }}$ damaged ship

\begin{tabular}{lll}
\hline Damage condition & $\mu$ & $\beta_{f}$ \\
\hline Collision (damaged area) & 3.34 & 2.57 \\
Grounding (damaged area) & 3.83 & 2.54 \\
& 3.81 & 2.36 \\
& 4.51 & 2.33 \\
\hline
\end{tabular}


Table 12 Safety indices for various mean values of change in SWBM $\left(K_{U S}\right)$ for intact and damaged area of damaged ship

\begin{tabular}{lll}
\hline Damage condition & $\mu$ & $\beta_{f}$ \\
\hline Collision (intact area) & 0.85 & 2.70 \\
Collision (damaged area) & 0.91 & 2.65 \\
& 0.72 & 2.59 \\
Grounding (intact area) & 0.79 & 2.53 \\
Grounding (damaged area) & 0.55 & 2.49 \\
& 0.65 & 2.41 \\
& 0.53 & 2.38 \\
& 0.63 & 2.30 \\
\hline
\end{tabular}

design (Parunov et al. 2007). For example, one can evaluate the effect of increasing or decreasing double bottom height or double side width on the structural safety after accidental damage. Such structural modifications could be particularly important because of the simultaneous effects on the probabilities of still water loads and ultimate strength.

One potentially useful practical application of the presented analysis is the determination of the maximum tolerable damage size. By proposing a target reliability level, the maximum size of the damage can be determined. However, it is clearly shown in the paper that such an analysis should consider the complex interaction of various load and strength parameters. It should also be emphasised that global wave loads, although reduced in respect of the typical design wave loads of intact ocean-going vessels, have clearly high influence on structural safety of damaged ships. Therefore, acceptable and tolerable damage sizes may be different for various wave environments.

Only vertical loads on the damaged ship structure were in the focus of this paper, although ships are subjected to combined vertical and horizontal loads. As improvement of the proposed procedure, the reliability calculation of damaged ship may be performed considering both vertical and horizontal loads (Khan and Das 2008; Jia and Moan 2008; Corak and Parunov 2020).

As a limitation of the presented method should also be mentioned, the heel angle due to asymmetrical flooding is not considered. The assumption is justified for full load

Table 13 Safety indices and failure probabilities for intact and damaged ship ('as-built' ship, CSR design)

\begin{tabular}{lll}
\hline Damage condition & $\beta$ & $P_{f}$ \\
\hline Intact & 3.33 & $4.36 \times 10^{-4}$ \\
Collision (intact area) & 3.06 & $1.10 \times 10^{-3}$ \\
Collision (damaged area) & 2.94 & $1.66 \times 10^{-3}$ \\
Grounding (intact area) & 2.83 & $2.32 \times 10^{-3}$ \\
Grounding (damaged area) & 2.71 & $3.30 \times 10^{-3}$ \\
\hline
\end{tabular}

Table 14 Safety indices and failure probabilities for intact and damaged ship ('corroded' ship, CSR design)

\begin{tabular}{lll}
\hline Damage condition & $\beta$ & $P_{f}$ \\
\hline Intact & 2.39 & $8.48 \times 10^{-3}$ \\
Collision (intact area) & 2.33 & $9.94 \times 10^{-3}$ \\
Collision (damaged area) & 2.22 & $1.32 \times 10^{-2}$ \\
Grounding (intact area) & 2.13 & $1.65 \times 10^{-2}$ \\
Grounding (damaged area) & 2.03 & $2.12 \times 10^{-2}$ \\
\hline
\end{tabular}

condition, as in that case heel angle is generally small. However, for other loading conditions, the effect of heel angle should also be accounted.

Another drawback of the presented approach is that consequences of collision and grounding are considered using statistics of damage size rather than considering causes of collision or grounding events and then calculating damage size by numerical simulation. Such approach of collision and grounding simulations would lead to more realistic damage scenarios.

\section{Conclusion}

The common SRA method for calculating the failure probability of an intact oil tanker is extended for the analysis of damaged tanker in collision or grounding accident. The reduction of ultimate bending capacity and changes in SWBM distribution are considered as random variables in the limit state function rather than constant values. Probability distributions of these random variables are derived in the present study based on the random damage characteristics proposed by IMO. The approach is also consistent with the IMO method for reliability assessment of the intact oil tanker. It can therefore be used by ship classification societies in the development of their rules for accidental limit states. The main advantage of the presented approach is that it includes in single limit state function consequences of random collision or grounding

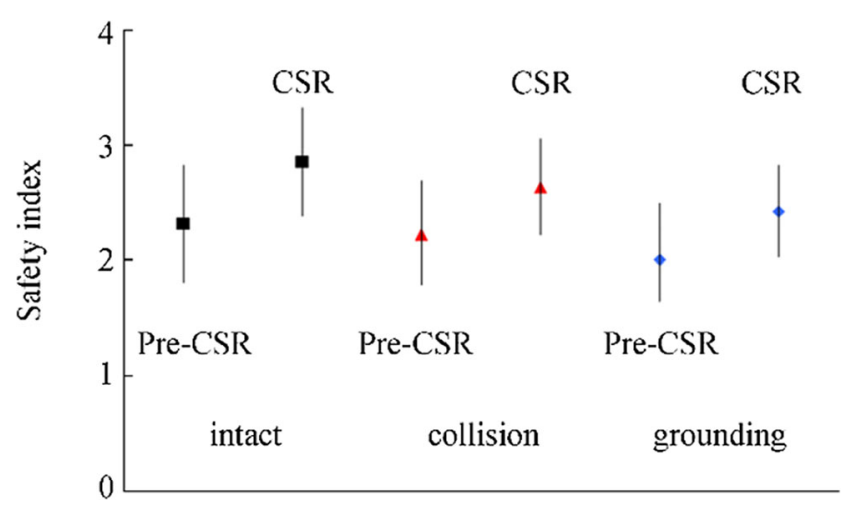

Figure 11 Ranges of reliability indices calculated by parametric variation 
damages, expressed as complex interaction of changes in the ultimate strength and still water loads. Such approach enables rational identification of the relative importance of the residual strength and SWBM in the ship structural design for accidental limit state that is not possible using deterministic or available reliability methods with prescribed damages.

Although not using novel methods, the present study has discussed the consequences of applying the approach prescribed in the Rules and has allowed relevant conclusions to be obtained, which may allow improvements in the state of the art. The most important conclusion from the presented SRA of a damaged oil tanker is that the change of SWBM caused by flooding of damaged compartments has a dominant influence on the structural reliability. Based on that conclusion, it could be recommended to classification societies to consider the SWBM distribution in damaged condition as the integral part of the verification procedure of the structural integrity of oil tanker regarding accidental limit state. It is shown in the present study that the loss in ultimate bending capacity because of the damage is less important than the SWBM and that the current rule approach, focusing on the calculation of the residual strength for one large damage with rather low occurrence probability may not be the most appropriate way to deal with accidental limit states.

Funding The work of the first two authors has been fully supported by the Croatian Science Foundation within the project 1P-2019-04-2085. This work contributes to the Strategic Research Plan of the Centre for Marine Technology and Ocean Engineering (CENTEC), which is financed by the Portuguese Foundation for Science and Technology (Fundação para a Ciência e Tecnologia - FCT) under contract UIDB/UIDP/00134/2020.

Open Access This article is licensed under a Creative Commons Attribution 4.0 International License, which permits use, sharing, adaptation, distribution and reproduction in any medium or format, as long as you give appropriate credit to the original author(s) and the source, provide a link to the Creative Commons licence, and indicate if changes were made. The images or other third party material in this article are included in the article's Creative Commons licence, unless indicated otherwise in a credit line to the material. If material is not included in the article's Creative Commons licence and your intended use is not permitted by statutory regulation or exceeds the permitted use, you will need to obtain permission directly from the copyright holder. To view a copy of this licence, visit http://creativecommons.org/licenses/by/4.0/.

\section{References}

ABS, DNV, Lloyd's register (2006) Common structural rules for double hull oil tankers

American Bureau of Shipping (1995) ABS 1995. Guide for assessing hull-girder residual strength for tankers

Begovic E, Day AH, Incecik A (2011) Experimental ship motion and load measurements in head and beam seas. 9th Symposium on High Speed Marine Vehicles. Italy, 1-8
Begovic E, Mortola G, Incecik A, Day AH (2013) Experimental assessment of intact and damaged ship motions in head, beam and quartering seas. Ocean Eng 72:209-226

Begovic E, Day AH, Incecik A (2017) An experimental study of hull girder loads on an intact and damaged naval ship. Ocean Eng 133: $47-65$

Bužančić Primorac B, Parunov J (2015) Probabilistic models of ultimate strength reduction of damaged ship. Trans FAMENA 39(2):55-74

Bužančić Primorac B \& Parunov J (2016) Review of statistical data on ship accidents. In: Guedes Soares, C. \& Santos T. A., (Eds.). Maritime Technology and Engineering 3; Taylor \& Francis Group; pp 809-814

Bužančić Primorac B, Ćorak M and Parunov J (2015a) Statistics of still water bending moment of damaged ship. Analysis and Design of Marine Structures, Guedes Soares C. \& Shenoi RA (Eds), Taylor and Francis Group, 491-497

Bužančić Primorac B, Slapničar V, Munić I, Grubišić V, Ćorak M, Parunov J (2015b) Statistics of still water bending moment of damaged Suezmax oil tanker. 18th International Conference on Ships and Shipping Research,Lecco, Italy, M. Altosole and A. Francescutto (Editors), 580-589

Campanile A, Piscopo V, Scamardella A (2018a) Comparative analysis among deterministic and stochastic collision damage models for oil tanker and bulk carrier reliability. Int J Naval Architect Ocean Eng 10:21-36

Campanile A, Piscopo V, Scamardella A (2018b) Conditional reliability of bulk carriers damaged by ship collisions. Mar Struct 58:321-334

Ćatipović I, Ćorak M, Parunov J, Alujević N (2019) Seakeeping experiments on damaged ship. Ships Offshore Struct, 14:sup1, 100-111

Ćorak M, Parunov J (2020) Structural reliability of oil tanker in the Adriatic Sea damaged in collision and exposed to combined bending moments. J Offshore Mech Arctic Eng - Trans ASME 142(3): 031103

Ćorak M, Parunov J, Guedes Soares C (2017) Structural reliability assessment of an oil tanker accidentally grounded in the Adriatic Sea. Proc. 36th International Conference on Ocean, Offshore and Arctic Engineering (OMAE2017), Trondheim, Norway, Paper OMAE2017-62278

Downes J, Moore C, Incecik A, Stumpf E and McGregor J (2007) A method for the quantitative assessment of performance of alternative designs in the accidental condition. 10th International Symposium on Practical Design of Ships and Other Floating Structures, Houston. 1025-1032

Faisal M, Noh SH, Kawsar MRU, Youssef SAM, Seo JK, Ha YC, Paik JK (2017) Rapid hull collapse strength calculations of double hull oil tankers after collisions. Ships Offshore Struct 12(5):624-639

Folsø L, Rizzuto E and Pino E (2008) Wave induced global loads for a damaged vessel. Ships Offshore Struct 3(4):269-287

Gaspar B, Guedes Soares C (2013) Hull girder reliability using a Monte Carlo based simulation method. Probabilistic Eng Mech 31:65-75

Gaspar B, Teixeira AP, Guedes Soares C (2016) Effect of the nonlinear vertical wave-induced bending moments on the ship hull girder reliability. Ocean Eng 119:193-207

Goerlandt F, Hanninen M, Stahlberg K, Montewka J, Kujala P (2012) Simplified risk analysis of tanker collisions in the Gulf of Finland. Int J Mar Navig Saf Sea Transp 6(3):381-387

Gordo JM, Guedes Soares C (1997) Interaction equation for the collapse of tankers and containerships under combined bending moments. $\mathrm{J}$ Ship Res 41(3):230-240

Gordo JM, Guedes Soares C, Faulkner D (1996) Approximate assessment of the ultimate longitudinal strength of the hull girder. J Ship Res 40(1):60-69

Guedes Soares C, Garbatov Y (1996) Fatigue reliability of the ship hull girder accounting for inspection and repair. Reliab Eng Syst Saf 51(3):341-351 
Guedes Soares C, Garbatov Y (1999) Reliability of corrosion protected and maintained ship hulls subjected to corrosion and fatigue. J Ship Res 43(2):65-78

Guedes Soares C, Ivanov LD (1989) Time-dependent reliability of the primary ship structure. Reliab Eng Syst Saf 26(1):59-71

Guedes Soares C, Teixeira AP (2001) Risk assessment in maritime transportation. Reliab Eng Syst Saf 74:299-309

Guedes Soares C, Dogliani M, Ostergaard C, Parmentier G, Pedersen PT (1996) Reliability based ship structural design. Trans Soc Naval Architects Marine Eng (SNAME), N Y 104:357-389

Guedes Soares C, Luís RM, Nikolov PI, Modiga M, Quesnel T, Dowes J, Toderan C, Taczala M (2008) Benchmark study on the use of simplified structural codes to predict the ultimate strength of a damaged ship hull. Int Shipbuild Prog 55(1-2):87-107

Heinvee M, Tabri K (2015) A simplified method to predict grounding damage of double bottom tankers. Mar Struct 43:22-43

Hirdaris S, Argiryiadis K, Bai W, Dessi D, Ergin A, Fonseca N, Gu X, Hermundstad OA, Huijsmans R, Iijima K, Nielsen UD, Papanikolau A, Parunov J, Incecik A (2014) Loads for use in the design of ships and offshore structures. Ocean Eng 78:131-174

Hussein AW, Guedes Soares C (2009) Reliability and residual strength of double hull tankers designed according to the new IACS common structural rules. Ocean Eng 36:1446-1459

International Association of Classification Societies (2000) IACS 2000 Recommendation No. 34: standard wave data. Rev. 1

International Association of Classification Societies (2014) IACS 2014. Common structural rules for bulk carriers and oil tankers

International Maritime Organisation (2003) IMO Revised Resolution MEPC 2003;110(49), Annex 16., Interim guidelines for the approval of alternative methods of design and construction of oil tankers under Regulation $13 \mathrm{~F}(5)$ of Annex 1 of MARPOL 73/78

International Maritime Organisation (2004) IMO, Maritime Safety Committee MSC 78/6/2. Goal-based new ship construction standards. Submitted by The Bahamas, Greece and IACS

International Maritime Organisation (2006) IMO Maritime Safety Committee MSC 81/INF.6. Goal-based new ship construction standards - linkage between FSA and GBS

International Maritime Organisation (2008) IMO MEPC 58/INF.2, 2008, Annex 1-3. Formal safety assessment

International Ships and Offshore Structures Congress (2015a) ISSC, Committee III.1. Ultimate strength, In: Guedes Soares, C. \& Garbatov Y., (Eds.). 19th International Ship and Offshore Structures Congress (ISSC 2015). Taylor \& Francis Group; pp. 279-349

International Ships and Offshore Structures Congress (2015b) ISSC in: Guedes Soares, C. \& Garbatov Y., (Eds.). 19th International Ship and Offshore Structures Congress (ISSC 2015). Taylor \& Francis Group pp. 520-590

Jensen JJ, Mansour AE (2002) Estimation of ship long-term wave-induced bending moment using closed-form expressions. The Royal institution of Naval Architects, W291

Jia H and Moan T (2008) Reliability analysis of oil tankers with collision damage. 27th International Conference on Offshore Mechanics and Arctic Engineering, Estoril, Portugal, paper OMAE2008-57102

Khan IA, Das PK (2008) Reliability analysis and damaged ships considering combined vertical and horizontal bending moments. Ships Offshore Struct 3(4):371-384

Kim DK, Kim HB, Mohd MH, Paik JK (2013) Comparison of residual strength-grounding damage index diagrams for tankers produced by the ALPS/HULL ISFEM and design formula method. Int J Naval Architect Ocean Eng 5:47-61

Lee Y, Chan H-S, Pu Y, Incecik A, Dow RS (2012) Global wave loads on a damaged ship. Ships Offshore Struct 7(3):237-268

Luís RM, Teixeira AP, Guedes Soares C (2009) Longitudinal strength reliability of a tanker hull accidentally grounded. Struct Saf 31(3): 224-233
Magoga T, Flockhart C (2014) Effect of weld-induced imperfections on the ultimate strength of an aluminum patrol boat determined by the ISFEM rapid assessment method. Ships Offshore Struct 9(2):218 235

Makouei SH, Teixeira AP and Guedes Soares C (2015) A study on the progressive collapse behavior of a damaged hull girder. Maritime Technology and Engineering, Guedes Soares C. \& Santos (Eds), Taylor \& Francis Group, London, 405-416

Mansour AE, Faulkner D (1973) On applying the statistical approach to extreme sea loads and ship hull strength. Trans Royal Inst Naval Architects (RINA) 115:277-314

Mikulić A, Parunov J, Guedes Soares C (2018) Wave-induced vertical motions and bending moments in damaged ships. J Mar Sci Appl 17(3):389-405

Muhammad Zubair MA (2013) Residual hull girder strength of asymmetrically damaged ships, $\mathrm{PhD}$ thesis, Graduate School of Engineering, Osaka University

Paik JK, Mansour AE (1995) A simple formulation for predicting the ultimate strength of ships. J Marine Sci Technol 1(1):52-62

Paik JK, Kim BJ, Seo JK (2008) Methods for ultimate limit state assessment of ships and ship-shaped offshore structures: part III hull girders. Ocean Eng 35:281-286

Paik JK, Kim DK, Park DH, Kim HB, Kim MS (2012) A new method for assessing the safety of ships damaged by grounding. Int J Marit Eng 154(A1):1-20

Paik JK, Kim DK, Park DH, Kim HB, Mansour AE, Caldwell JB (2013) Modified Paik-Mansour formula for ultimate strength calculation of ship hulls. Ships Offshore Struct 8(3-4):245-260

Papanikolaou A, Bulian G, Mains C (2011) Goalds, goal-based damaged stability: collision and grounding damages. In: Proceedings of the 12th International Ship Stability Workshop. 37-44

Parunov J, Guedes Soares C (2008) Effects of common structural rules on hull-girder reliability of an Aframax oil tanker. Reliab Eng Syst Saf 93:1317-1327

Parunov J, Senjanović I, Guedes Soares C (2007) Hull-girder reliability of new generation oil tankers. Mar Struct 20(1-2):49-70

Parunov J, Ćorak M, Gledić I (2015) Comparison of two practical methods for seakeeping assessment of damaged ships, In: Guedes Soares C, Shenoi RA (eds) Analysis and Design of Marine Structures, Taylor \& Francis Group, London, pp 37-44

Parunov J, Ćorak M, Rudan S (2017a) Correlation analysis of IMO collision damage parameters. In: Guedes Soares C, Garbatov Y (eds) Progress in the Analysis and Design of Marine Structures. Taylor \& Francis Group, pp 477-485

Parunov J, Rudan S, Ćorak M (2017b) Ultimate hull-girder-strengthbased reliability of a double-hull oil tanker after collision in the Adriatic Sea. Ships Offshore Struct 12(S1):55-67

Parunov J, Rudan S, Bužančić Primorac B (2017c) Residual ultimate strength assessment of double hull oil tanker after collision. Eng Struct 148:704-717

Parunov J, Ćorak M, Guedes Soares C, Jafaryeganeh H, Kalske S, Lee Y, Liu S, Papanikolaou A, Prentice D, Prpić-Oršić J (2020) Benchmark study and uncertainty assessment of numerical predictions of global wave loads on damaged ships. Ocean Eng 197(106876):24. https:// doi.org/10.1016/j.oceaneng.2019.106876

Prestileo A, Rizzuto E, Teixeira AP, Guedes Soares C (2013) Bottom damage scenarios or the hull girder structural assessment. Mar Struct 33:33-55

Ringsberg JW, Amdahl J, Chen BQ, Cho SR, Ehlers S, Hu ZQ, Kõrgesaar M, Liu B, Nicklas K, Parunov J, Samuelides M, Guedes Soares C, Tabri K, Quinton BW, Yamada Y, Zhang SM (2018) MARSTRUCT benchmark study on nonlinear FE simulation of an experiment of an indenter impact with a ship side-shell structure. Mar Struct 59:142-157

Saydam D, Frangopol DM (2013) Performance assessment of damaged ship hulls. Ocean Eng 68:65-76 
Sun BC, Zhang Y, Li FW, Jiang XL, Lodewijks G (2014) (2015) Systems structure and simulation design of emergency response to maritime accidents. In: Guedes Soares C, Santos TA (eds) Maritime Technology and Engineering. Taylor \& Francis Group, London, pp 235-241

Tagg R, Bartzis P, Papanikolaou A, Spyrou K, Lützen M (2002) Updated vertical extent of collision damage. Mar Struct 15(4-5):475-498

Teixeira AP, Guedes Soares C (2009) Reliability analysis of a tanker subjected to combined sea states. Probabilistic Eng Mech 24(4): 493-503

Teixeira AP, Guedes Soares C (2010) Reliability assessment of intact and damaged ship structures. Advanced ship Design for Pollution. Guedes Soares C \& Parunov J (Eds), Taylor \& Francis Group, London, 79-93

Teixeira AP, Guedes Soares C and Wang G (2005) Reliability based approach to determine the design loads for the remaining lifetime of ship hulls. Maritime Transportation and Exploitation of Ocean and Coastal Resources - Guedes Soares, Garbatov \& Fonseca (eds), Taylor \& Francis Group, London, 1611-1619

Teixeira AP, Parunov J, Guedes Soares C (2011) Assessment of ship structural safety. In: Guedes Soares C, Garbatov Y, Fonseca N, Teixeira AP (eds) Marine Technology and Engineering. Taylor \& Francis Group, London, pp 1377-1394

Wang G, Yongjun C, Hanqing Z, Hua P (2002) Longitudinal strength of ships with accidental damages. Mar Struct 15:119-138

Xu MC, Teixeira AP, Guedes Soares C (2015) Reliability assessment of a tanker using the model correction factor method based on the IACSCSR requirement for hull girder ultimate strength. Probabilistic Eng Mech 42:42-53

Youssef SA, Faisal M, Seo JK, Kim BJ, Ha YC, Kim DK, Paik JK, Cheng F, Kim MS (2016) Assessing the risk of ship hull collapse due to collision. Ships Offshore Struct 11(4):335-350

Zayed A, Garbatov Y, Guedes Soares C (2013) Time variant reliability assessment of ship structures based on fast integration techniques. Probabilistic Eng Mech 32:93-102 